\title{
The Efficacy of the SECI Model for the Training of High School Teachers in Relation to Gender Equality in Vietnam
}

\author{
Mai Thi Thuy Dung ${ }^{1, *}$, Mark Brundrett ${ }^{2}$ \\ ${ }^{1}$ Ho Chi Minh City University of Education, \\ 280 An Duong Vuong, District 5, Ho Chi Minh City, Vietnam \\ ${ }^{2}$ Liverpool John Moores University, UK
}

Received 15 May 2021

Revised 26 July 2021; Accepted 08 August 2021

\begin{abstract}
Vietnamese government policy has been one of complete equality of opportunity in schools and in wider society, both as a commitment to social justice and as a way of enhancing the economy of the nation by facilitating and encouraging much greater inclusion of women in economic activity. One of the main aims of the research reported in this article was to trial programmes of training for teachers and teacher education students about gender equality in education using the model of Socialisation, Externalisation, Combination and Internalisation (SECI), first developed in Japan, which integrates knowledge acquisition with social learning activities (Nonaka and Takeuchi, 1995). The response to the programme of training using the SECI model was positive, suggesting that this approach may be an effective model for both Initial Teacher Education and Continuing Professional Development for High School Teachers in Vietnam.
\end{abstract}

Keywords: Gender equality, teacher training, SECI model, high school teachers, teacher education.

\section{Introduction}

Vietnam has made great efforts in promoting gender equality in the last decade based on the enactment of the Law on Gender Equality in 2006 and the Law on Prevention and Control of Domestic Violence in 2007 [1]. There is, however, significant evidence that there remains a gap between the rhetoric and reality of equality of opportunity in Vietnamese

\footnotetext{
${ }^{*}$ Corresponding author.

E-mail address: dungmtt@hcmue.edu.vn

https://doi.org/10.25073/2588-1159/vnuer.4530
}

High Schools and that the lack of knowledge about gender equality amongst high school teachers has a major deleterious effect on the school outcomes and the subsequent life chances of girls [2].

This study builds on previous work in relation to teacher training on the use of SECI model in Thailand educational contexts by Brundrett and Lungka [3]. It attempts to address these issues by trialling an approach to leadership training in Vietnamese High Schools which employs the Socialisation, Externalisation, Combination and Internalisation (SECI) model which was first developed in Japan by Nonaka and Takeuchi 
[4]. The model was originally developed for Japanese business management settings and, despite being employed more widely, has still received comparatively little attention in educational settings [3]. The attraction of the SECI model is its commitment to integrate knowledge acquisition with group activities for individuals to interact [4].

The project was based on a multi-site case study in Vietnam using a mixed methods approach. Focus group interviews and semi-structured interviews were used to collect qualitative data and questionnaires were used which added a quantitative element to the study.

The main objectives of the study were:

i) To develop and deliver programmes of training to teachers and teacher education students using SECI model in order to trial an approach to enhancing gender equality across the sector;

ii) To conduct research to examine, analyse and subsequently delineate the efficacy of these programmes and the ways in which they might be improved in order that this approach might be made scalable for regional and national roll out.

\section{Background to the Study}

\subsection{Gender Equality in Vietnam}

Vietnamese society has been deeply affected by Confucianism, which gives prominence to men in key roles in both families and wider society [5]. Nonetheless, in recent years, the Vietnamese government has made considerable progress in targeting gender stereotypes in every aspect of the society, most notably by establishing the Law on Gender Equality in 2006 [6] and, more recently, through National Strategies for Gender Equality for the 2011-2020 Period [7]. Indeed, Vietnamese government policy has, for some time, been one of complete equality of opportunity in society as a commitment to social justice and as a way of enhancing the economy of the nation by facilitating and encouraging the inclusion of women in economic activity. However, the implementation of legislation and Vietnamese government policy regarding gender equality remains a significant challenge [1].
There is a considerable body of research, which has shown that in Vietnam, women have been facing serious obstacles in their daily lives and that they have limited access to Higher Education and in employment [1]. The percentage of the population that is literate at 15 years of age has always been higher for males than for females' [8]. In 2020, there were 26.2 million female workers, which contributed $47.5 \%$ to the labour force of the country [9], however, 79\% of employed women workers had no official training [9]. The ratio of females was higher than males in agriculture, whilst the opposite was true in the industrial sphere [9]. Most notably, females' earnings are lower than those of males in all economic and geographical areas of the country [9]. This inequality "acutely affects the performance and outcomes" of the country (Harris and Jones, 2018:1) [11].

In education, female staff outnumber male staff by a considerable number, especially in primary and lower secondary education [8]. In the school year 2016-2017, the percentage of female teachers was $73.4 \%$ in primary schools, $68.4 \%$ in secondary schools, $63.5 \%$ in high schools and $47.9 \%$ in universities [8].

The number of female students in colleges and universities has increased slightly in recent ten years [8], but the social norms about appropriate occupations for men and women that children have learned from a young age have an influence on their educational choices and, as the consequence of this, women often choose to work in low-paid jobs [10]. Meanwhile, in schools, boys wish to maintain the current gender roles and stereotypes [12]. It is evident that gender equality in education in that country is espoused rather than enacted [2]. Teachers' awareness about gender equality could, with appropriate training and support, play an important role in challenging such stereotypes.

\subsection{The SECI Model}

The SECI model is a knowledge creation process that was developed by Nonaka and Takeuchi in the 1990s [4]. They posit that humans construct and disseminate knowledge 
via the inter-relationship between explicit knowledge and tacit knowledge (Nanoka and Takeuchi, 1995:61) [4]. According to the formulation, since explicit knowledge can be presented in formal systematic language in different forms such as data or manuals, "it can be processed, transmitted and restore" (Nonaka, Toyama and Konno, 2000:7) [13]. By contrast, tacit knowledge is personal and based heavily on individuals' actions and experience; hence it is very subjective and "difficult to communicate" (ibid, pp. 7). Both types of knowledge are required if an individual is to gain full mastery of a topic.
The SECI model seeks to ensure that those undergoing training are imbued with both types of knowledge and consists of four different modes of knowledge conversion: i) Socialisation (sharing tacit knowledge to develop tacit knowledge); ii) Externalisation (transforming tacit knowledge into explicit knowledge); and iii) Combination (integrating explicit knowledge) and Internalisation (converting explicit knowledge into tacit knowledge) (Nonaka, Toyama and Konno, 2000:9) [4, 13], as represented in Figure 1, below.

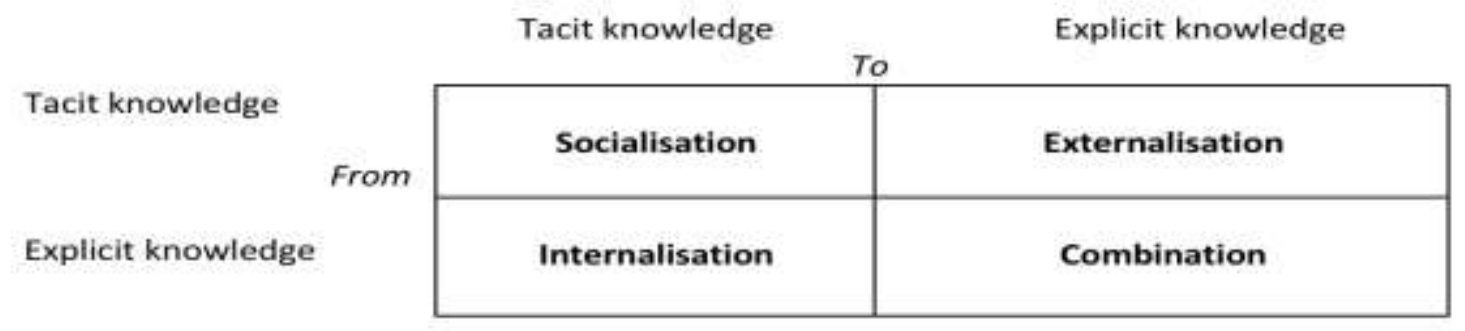

Figure 1. Four modes of knowledge conversion (Nonaka and Takeuchi, 1995:65) [4].

The interaction between tacit knowledge and explicit knowledge will start at the individual level and later develop to a larger scale [4]. Importantly, since "knowledge is created through the interactions amongst individuals or between individuals and their environments" (Nonaka, Toyama and Konno, 2000:8) [13], creating an environment that encourages individuals to interact and exchange their knowledge would be beneficial in enhancing the awareness of each individual about specific areas of knowledge (ibid). With this in mind, the training programme for teachers and teacher education students was developed and analysed for its efficacy.

\section{Methodology}

The research approach was a case study that employed "a small number of highly focused interviews as a key methodological approach" (Burton, Brundrett and Jones, 2008:80) [14]. A mixed methodology, which used mainly qualitative approaches but with an element of the quantitative, was employed to exploit the strengths of both traditions of inquiry [15] although the main approach was qualitative.

The sample was developed in a university of teacher education and two high schools based in socially and geographically contrasting locations in Vietnam. The university was one of the leading universities of teacher training in that country and 30 first, second and third year teacher students from eight different subject areas were chosen to take part in the training programme. The first high school, with approximately 750 students, was located in Ho Chi Minh City which is the largest metropolitan area in Vietnam. The second school was located Dak Lak province, in the central highlands of the country, and was a primary-secondary-high school, also with approximately 750 students. A Deputy Head teacher, a subject leader and two subject teachers were interviewed in each school in order to provide data on a cross-section of the leadership structure of the schools. 
The study was conducted using multiple methods, including focus group discussions, semi-structured interviews and questionnaires. A two-hour training session was delivered, based on the SECI model, in each location that focused on enhancing gender equality in Vietnamese High Schools. The number of respondents included 22 teachers of different roles, genders and experience in the first high school and 32 teachers in the second high school. In each session, the trainer made a presentation on gender equality in education in Vietnam, comparing the situation in that nation with other jurisdictions, such as England, for 15 minutes. A successful woman entrepreneur was invited as a guest speaker to share her experience and emphasize the importance of gender equality in education and Vietnamese society for the next 20 minutes. Then participants discussed the topic in groups based on key issues provided by the trainer. One of the members of each group was elected to present what they had discussed with other members of the group interjecting with their own comments. Each group also analysed what their schools could do to promote gender equality in education and produced a leaflet that might inform other staff about their agreed findings. The leaflets were subsequently shared amongst all participants. Finally, the delegates completed questionnaires to gain feedback about the training session. On the next day, after time for reflection, four teachers were interviewed individually in each school for about half an hour per respondent. The same procedure was carried out with the student teachers but without individual interviews.

The programme was structured especially to expedite the four modes of knowledge conversion proposed in the SECI model.

\section{Evaluations of Programme of Training}

It should be highlighted that there were misunderstandings amongst teacher education students about gender equality and, thus, they asked the trainer many questions about its meaning. $60 \%$ (18 out of 30 ) of students related equality to national policies such as the differing retirement ages for men and women operant in Vietnam, the restrictions on girls in terms of access to certain jobs and other issues such as discriminatory attitudes towards fathers who do not have a son, the patriarchy in their own family and their own experience in terms of gender roles. Notably, however, $100 \%$ (84 out of 84) of respondents stated that the training had helped them to gain more knowledge in this area and that they acknowledged the benefits of having greater gender equality and the time to reflect on this topic. An example of this came from a student in one of the university groups, who stated:

We have a better viewpoint about gender equality and we had more knowledge about this. We might have overheard things somewhere in the past but it was very scant and now it was delivered to us properly.

(Male student of Physics)

The comments of teachers about the efficacy of the training were also positive. Responses confirmed that they felt they had better awareness of gender issues and that they could begin integrating them into their teaching activities. Indeed, it was suggested that they required further such opportunities:

I think we should have two or three training sessions like this in a year because after discussions, our awareness was improved, like being awakened. Like I used to think that teaching my subject is more important than anything, more than contributing to promoting gender equality for students. We've undervalued it. We were not awake...You've shown us a vivid picture. After discussions, we've realised that it looked normal but it was actually not normal (gender inequality).

Or

Head subject female teacher)

I think this is a really good one. I myself can differentiate between sex and gender terms. I only knew about the term in relation to "sex" before and I thought that they were the same. Now I know what gender stereotypes are and that gender stereotypes can be challenged.

(Newly qualified male teachers) 
Many of participants were pleased with the training as it allowed them to share their opinions freely as well as to connect colleagues when discussing in groups. To some extent, they also changed their viewpoints about gender equality and they all admitted the necessity of the training not only for their own schools but also for other High Schools nationally. However, some stated that the time for discussion and the guest speaker was not efficient as they wanted to exchange more ideas. The guest speakers' stories were, however, especially highly appreciated by all the participants in the different locations. A female student said:

It was a good chance to listen to the experience of the guest speaker and speak to her. We feel like we are more confident about ourselves and our future jobs: we can become managers. It also helps boys to have a different attitude towards us. We often see that managers are men. All the Head teachers in my schools were men. I really admire the guest speaker.

Equally, the judgement of a male student of History was that the training was: "very useful. Real-life person guest speaker could help girls to consider her as a role model to have high self-esteem. And boys can have a proper acknowledgement about roles of women". Similar appreciation was also acknowledged by teachers; for example, a female teacher with twenty-three years of experience stated: "The guest speaker was so impressive. She was a role model indeed. Her stories were so honest, her answers were simple and right what we'd like to hear'.

It was also clear that many respondents wished to learn more with several stating that they wished to see pictures and videos of high schools in England that provided exemplars of the ways in which gender equality was led and managed as well as details of websites from which they could learn more. The leaflets and notes made in the study groups showed that participants believed that they and their schools could do more to promote gender equality, however, they felt that their ability to engender improvements was curtailed by their lack of knowledge and they wanted to be provided with practical detailed strategies to follow. Notably, all participants stated that there should be a subject strand or a module on gender equality in ITT.

It was interesting to note that, in general, teachers stated that they were not interested in more "traditional" forms of training that focused on lengthy input by lecturers since they considered such training was not useful and they expressed severe doubts about the effectiveness of such approaches. Some judgements of teachers were:

"There was hardly any effective training. It is all impractical" (newly qualified male teacher)

And

"(Traditional) Training espouses things but doesn't do anything. As time goes by, everything turns back to the previous state. Trainers are not professional and they themselves don't do what they say" (highly experienced male teacher)

For most of the teachers, this model of training was new in that it included the involvement of guest speakers, activities, with less time for lecturing but more time for discussion compared to other trainings that they had attended. It was also deemed important that participants could also give their feedback on the training via discussions, questionnaires and interviews. Undoubtedly, participants received this training positively, largely because they had chances to reflect on practice, and discuss and express their opinions.

According to the data collected, the programme of training was considered as an appealing one because of its content, outcomes and overall model. It was also viewed as having the potential to be more effective in terms of time taken up. Participants recommended that such training sessions should be carried out in all schools in the country, not only in high schools but also in secondary and primary schools.

\section{Discussion}

The research displayed the degree of the absence of both and understanding and effective action about gender equality in the two high 
schools and the university of teacher education involved in the study. It was, though, pleasing to note that participants welcomed the programme of training that was delivered as part of this study and the SECI approach was viewed with considerable enthusiasm. The responses of participants revealed that many recognised the importance of gender equality after training.

\subsection{The Efficacy of the Training Programme in Enabling and Encouraging Teachers to Enhance Gender Equality in High Schools}

The programme was successful in awakening the awareness of stakeholders on gender issues and thus, it seems clear that programmes of this type would be beneficial to students, especially girls. It was evident that teachers and student teachers gained more knowledge about gender equality and they were better aware of gender issues in the educational environment. One cannot judge, definitively, whether this apparent efficacy was related to the application of the SECI model but it is noteworthy that the SECI model focuses on both receiving knowledge and creating knowledge [4] and both these elements were required in order to enable teachers not only to receive but also to internalise said knowledge and to act upon it. During discussions, participants had opportunities to share their experience and knowledge with their colleagues before blending it with the theoretical knowledge that they had been exposed to. This process allowed them not only to learn new knowledge from others but also reflect on what they themselves as teachers could do in their own practice.

This training programme was considered as a new model of training as it had one element of input from the researcher, one element of input from a guest speaker discussing their personal life history, and a final element that allowed the majority of time for teachers to socialise, brainstorm, discuss and reflect. The main topic in focus was not gender equality in theory but gender equality in relation to classroom and school practice that was more practical and easier to implement. Most importantly, the appreciation expressed by teachers, school leaders and students towards this programme provided powerful evidence that one may deem this a persuasive model for teacher training and especially for continuing development programmes for teachers in order to improve their awareness about gender equality in education.

\subsection{An adapted SECI Model for a Programme of Training for Teachers and Students}

The programme of training reported here was developed based on an adapted SECI model which focused, like the original, on knowledge transfer and knowledge creation. The SECI model has been researched and employed widely, especially in business organisations [4] but it is rarely applied to educational contexts [3]. Brundrett and Lungka (2018) [3] had carried out a training programme using SECI model for Early Years teachers in Thailand and it was a success. In Vietnam, indeed, the researchers can state with some confidence that this case is one of the first when a programme based on the SECI approach was employed for the training of teachers and students with the aims to improve knowledge in promoting gender equality in education.

The programme was designed to adopt the four processes of the SECI model that include: socialisation, externalisation, combination and internalisation [4]. The process can be explained as the following:

i) Socialisation occurred when teachers and students were encouraged to share their experience through group discussions. The purpose of this phase was to allow them to talk and share experience. By doing this, they listened to each other's experience and learned from each other. In the SECI model, this socialisation is "the process of converting new tacit knowledge through shared experience" (Nonaka, Toyama and Konno, 2000:5) [13];

ii) Externalisation happened when participants were indirectly required to transfer their tacit knowledge shared in the socialisation phase to explicit knowledge through a brainstorming activity. They had to conceive 
what they themselves and their schools could do to promote gender equality in education. In order to do this, they expressed their knowledge and used discussion to persuade other people about why and how they would do it;

iii) Combination took place when the explicit knowledge formulated in the externalisation phase was arranged, combined or adjusted into "more complex and systematic sets of explicit knowledge" (Nonaka, Toyama and Konno, 2000:9) [13]. In groups, participants discussed, exchanged and modified the explicit knowledge before producing a leaflet showing what they could do to enhance gender equality in their schools. This process allowed them to systemise different explicit knowledge and express this as new knowledge. The leaflets were presented to all other groups as a reference for teachers and schools to use in the future.

iv) Internalisation was the desired final phase when participants embodied experiences gained through socialisation, externalisation and combination into their own tacit knowledge individually [4]. Participants converted what they had learned, through the shared experience in the socialisation phase, discussions in the externalisation phase and knowledge from the shared leaflets into their tacit knowledge.

Eventually, when participants impart what they learned and created in the training to their students and colleagues through socialisation, a new spiral of knowledge creation will begin.

This study reveals strong evidence that an adapted SECI model could be applied effectively in a programme of training for teachers. As elucidated above, all activities that took place during the training were designed carefully based on the SECI model in order to transfer tacit knowledge to tacit knowledge; make tacit knowledge into explicit knowledge; and to integrate different explicit knowledge and convert explicit knowledge into tacit knowledge [4]. The programme enabled greater development of knowledge by teachers imparting their knowledge to a broader audience and they would reflect themselves in their own practice. The researchers feel that a persuasive case can be made that the SECI model is an appealing approach to teacher development.

Despite the assertion above, however, it is important to note that there are elements that may influence on the outcomes when using SECI model in this type of programme. It was clear that a comfortable environment that encourages participation and sharing of teachers is crucial since teachers must feel free to express their ideas and experience. The appointment or election of a group leader was important in order to facilitate and manage group activities which might include individuals of different genders, and different positions in the relevant social hierarchy and hold contrasting opinions. The selection of such group leaders is potentially challenging since the aim should be to ensure equity and prevent dominant individuals from controlling the agenda. In this study, in the school-based training events, groups were selected to be representative of a cross-section of respondents including those of different genders and different career points. The groups then selected their own leaders and because of the social dynamics that inevitably became operant, most group leaders were senior teachers. It is interesting to note that whilst these individuals dominated the externalisation and combination phases, less experienced teachers appeared dominant in the socialisation and internalisation phases. Other key points to note were that, since the topic of the programme is one that is affected deeply by cultural norms, the outcomes relied heavily on politics (both macro and micro), the level of acceptance of the personal professional learning process and the overall degree of engagement of teachers.

\section{Conclusion}

The findings of the study provide convincing evidence that teachers, school leaders and students gained more knowledge and experience about gender equality in education after training based on the SECI model and such an approach could form the basis for an effective future model of continuing 
development programme for teachers in Vietnam. Undoubtedly, the appropriate timing of sessions and the inclusion of more exemplars of best practice would need to be considered carefully in order to enhance satisfaction levels further. There is also evidence that teacher education programmes need to dedicate an appropriate amount of time for learning in relation to gender equality in education and this topic should be included in the syllabus for teacher training institutions [2]. Programmes of training based on the SECI model or other models that integrate reflection and socialisation, are likely to be most effective in addressing the issue of gender equality in schools in Vietnam.

Even when this programme had ignited interest in this issue, school leaders still stated that they awaited clear policy and guidance on this matter rather than themselves actively commencing plans for change. This calls into question the role of school leaders and the raises questions about the issues surrounding their reticence in this area. School success in Vietnam is currently inextricably linked to examination results which diminishes the time available for other initiatives. This focus, allied to the social and cultural issues which may be called into question if gender equality is to be tackled with appropriate rigour and seriousness may well offer an explanation of why school leaders feel disempowered in this area unless supported by further training and guidance. Thus, the researchers posit that a training policy and associated guidance should be provided for school leaders as a matter of urgency.

The researchers would argue that further trialling on a larger scale should take place of the type of training activity reported here across all phases of the education sector in Vietnam alongside a study to evaluate the perpetuation and impact on practice after training. Indeed, research should be encouraged and enabled into the wider issues raised in this study including the nature school leadership and continuing professional development for teachers all stages of education system in Vietnam.

\section{References}

[1] United Nations, Cross-cutting Themes: Gender, http://www.un.org.vn/index.php?option=com_conte nt\&view=article\&id=1081\%3Across-cuttingthemes-gender\&catid=116\%3Awhat-wedo\&lang=en/, 2018 (accessed on: April 27 $7^{\text {th }}, 2018$ ).

[2] M. Brundrett, D. Mai, The Challenge of Ensuring Gender Equality in Vietnamese and English High Schools: Espoused and Real Commitments, International Journal of Comparative Education and Development, Vol. 20, No. 1, 2018, pp. 2-15.

[3] M. Brundrett, P. Lungka, The Development of Teachers' Knowledge and Behaviour in Promoting Self-discipline: a Study of Early Years Teachers in Thailand, Education 3-13 International Journal of Primary, Elementary and Early Years Education, Vol. 47, No. 4, 2018, pp. 462-474.

[4] I. Nonaka, H. Takeuchi, The Knowledge-creating Company, Oxford University Press, New York, 1995.

[5] T. M. D. Tran, X. D. Hoang, H. Do, Gender Bias and Discrimination: Theory and Practice, Hanoi National University Publisher, Hanoi, 2006 (in Vietnamese).

[6] Vietnamese Ministry of Justice, Gender Equality Law, http://moj.gov.vn/vbpq/lists/vn\%20bn\%20php\%20lut/v iew_detail.aspx?itemid=14854/, 2006 (accessed on: April 27 ${ }^{\text {th }}$, 2018) (in Vietnamese).

[7] The Socialist Republic of Vietnam, National Strategy on Gender Equality for the 2011-2020 Period, http://www.chinhphu.vn/portal/page/portal/English/s trategies/strategiesdetails?categoryId $=30 \&$ articleId $=$ 10050924/, 2012 (accessed on: April 30 ${ }^{\text {th }}, 2021$ ).

[8] GSO, Investigation of Population and Accommodations 2014: Proportions of Age, Gender and some Socio-economic Issues in Vietnam, Information Publisher, Hanoi, 2016 (in Vietnamese).

[9] GSO, Report of Investigation of Labour Force and Occupations, Fourth Quarter 2020, General Statistics of Vietnam, https://www.gso.gov.vn/du-lieu-va-solieu-thong-ke/2021/05/bao-cao-lao-dong-viec-lamquy-4-nam-2020/, 2021 (accessed on: June $6^{\text {th }}, 2021$ ) (in Vietnamese).

[10] I. Chowdhury, H. Johnson, A. Mannava, E. Perova, Gender Gap in Earnings in Vietnam: Why Do Vietnamese Women Work in Lower Paid Occupations? Asia and Pacific, EAP GIL Policy Briefs, Worldbank Group, Washington, D.C, 2018.

[11] A. Harris, M. Jones, Leading Against the Odds, School Leadership and Management, Vol. 38, No. 1, 2018, pp. 1-3. 
[12] UNESCO, Reaching Out: Preventing and Addressing School-related Gender-based Violence in Vietnam, UNESCO, France, 2016.

[13] I. Nonaka, R. Toyama, N. Konno, SECI, Ba and Leadership: a Unified Model of Dynamic Knowledge Creation, Long Range Planning, Vol. 33, 2000, pp. 5-34.
[14] N. Burton, M. Brundrett, M. Jones, Doing Your Education Research, Sage, London, 2008.

[15] M. R. Harwell, Research Design in Qualitative/Quantitative/Mixed Methods, in C. F. Conrad, R. C. Serlin, (eds) The SAGE Handbook for Research in Education, Pursuing Ideas as the Keystone of Exemplary Inquiry, Sage, London, 2011, pp. 147-163. 